\section{$\underset{\substack{\text { hommes } \\ \text { \& migrations }}}{ }$}

\section{Hommes \& migrations}

Revue française de référence sur les dynamiques

migratoires

$1281 \mid 2009$

France-Brésil sous l'angle des migrations et de l'altérité

\title{
Pierre Assouline, Les Invités
}

Gallimard, 2009, 207 pages, 17,90 euros

\section{Mustapha Harzoune}

\section{OpenEdition}

\section{Journals}

Édition électronique

URL : http://journals.openedition.org/hommesmigrations/426

DOI : 10.4000/hommesmigrations.426

ISSN : 2262-3353

Éditeur

Musée national de l'histoire de l'immigration

Édition imprimée

Date de publication : 1 septembre 2009

Pagination : 216-217

ISSN : 1142-852X

\section{Référence électronique}

Mustapha Harzoune, "Pierre Assouline, Les Invités », Hommes \& migrations [En ligne], 1281 | 2009, mis en ligne le 29 mai 2013, consulté le 22 septembre 2020. URL : http://journals.openedition.org/ hommesmigrations/426; DOI : https://doi.org/10.4000/hommesmigrations.426

Ce document a été généré automatiquement le 22 septembre 2020

Tous droits réservés 


\title{
Pierre Assouline, Les Invités
}

\author{
Gallimard, 2009, 207 pages, 17,90 euros
}

\author{
Mustapha Harzoune
}

\section{RÉFÉRENCE}

Pierre Assouline - Les Invités, Gallimard, 2009, 207 pages, 17,90 euros

1 Pierre Assouline, journaliste, romancier, essayiste, biographe (Marcel Dassault, Simenon, Gaston Gallimard, Jean Jardin, Kahnweiler, Albert Londres ou encore Hergé) et blogueur à succès, aborde, avec Les Invités, la difficile question de l'identité, du rapport à l'Autre, des préjugés et des imaginaires nationaux qui emprisonnent et blessent les nouveaux venus.

2 Tout cela est traité de manière originale : un dîner. Un dîner au cœur du VIIe arrondissement de Paris, où s'épanouit, hautaine et dominatrice, une grande bourgeoisie fière de donner à la nation tout entière le "la" des us et coutumes.

3 Ce soir, ce sont Sophie du Vivier et son époux Thibault qui régalent. Ils ont convié Stanislas Sévillano, "célibataire confirmé" ; "Son-Excellence-Alexandre" et sa femme MarieDo ; Erwan et Sybil Costière, de la belle graine de nouveaux riches, "formatés plutôt que formés" ; les Le Châtelard, lui Adrien, avocat de renom, et elle Christina, "la présence" énigmatique... George Banon campe un industriel canadien avec qui Thibault souhaiterait bien conclure un contrat. Joséphine, directrice de programme sur une chaîne câblée, incarne le monde peu flatteur des médias. Enfin, pour ce texte, spirituel et littéraire à souhait, les Dandieu. Lui est écrivain et membre de l'Académie française.

Sans oublier Sonia, la bonne ! Ainsi prénommée par sa patronne qui trouve son prénom imprononçable et sans doute bien malséant : Oumelkheir.

Pour ne pas être treize à table, elle se retrouve au milieu des convives qu'elle était censée, quelques minutes auparavant, servir et desservir. Très vite, sous les traits de Sophie, Oumelkheir sera démasquée par la perfide Marie-Do. La prouesse d'Assouline est d'avoir transposé autour de cette table les tensions intérieures, les pressions subies, 
les peurs et les angoisses, mais aussi le regard distancé, amusé, parfois moqueur, de l'étranger, de l'immigré ou du Français "de branche", candidat à une communauté de destin national avec ces Français de souche ou supposés tels.Ici, c'est la France qui est à table, tandis que le clandestin s'active et ronge son frein en cuisine. Une France qui refuserait de se voir et de se reconnaître pour ce qu'elle est devenue depuis des lustres. Le conflit de classe s'emberlificote, donc l'arantèle identitaire.

Bien sûr, Sonia-Oumelkheir, qui n'aspirait à rien d'autre qu'à la paix, occupera le centre des discussions. Cette Française aux lointaines origines marocaines, née à Marseille du côté de l'Éstaque, en remontrera à ses commensaux d'un soir. Mais, que de pressions et d'anxiétés! Il lui faut être à la hauteur, ne pas choquer, ne pas risquer de perdre sa place. D’être renvoyée! En silence, elle essuie les incompréhensions, les fautes de goût, les rebuffades, les cruautés. Pour une furtive complicité, combien de honte bue, de paroles restées coincées au travers de la gorge, de vexations, de doigts de pieds tordus plutôt que de "laisser échapper un cri, un mot, une humeur".

7 Les sujets de discussion n'étonneront pas : la prononciation impossible du curieux prénom ; les "discriminations positives" et autres passe-droits offerts aux "pauvres" qui, comme Sonia-Oumelkheir, réussissent à se hisser au-dessus de la mêlée. Et d'ailleurs, est-elle entièrement Française ? La culture ou le pays d'origine sont réduits à un exotisme touristique, de même que les immigrés et leurs descendants français se voient réduits à une population arabe et musulmane : "Tout ça c'est pareil !" Rien ne sera épargné à la jeune femme, jusqu'au : "Et vous vous plaisez chez nous?" Encore et toujours considérée au mieux comme une invitée au pire comme une intruse. Viennent ensuite les poncifs sur la langue arabe réduite à des "appels au meurtre ou à l'apologie de la terreur " (il faut relire Assia Djebar) et, bien sûr, des incontournables : l'islam, l'excision, la circoncision, les vertus comparées du métissage à la canadienne et de l'intégration à la hussarde républicaine, le regroupement familial, les "victimes professionnelles", le dénigrement des médecins diplômés à l'étranger qui officient à l'hôpital public...

8 Comme le confie Banon à Sonia : "votre présence a fait sortir des choses qui ne sortent jamais. Tout ce que la société enfouit en espérant que jamais personne n'aura le mauvais goût de le déterrer. Il suffit de pas grand-chose. Treize et puis... Toute la poussière sort, fait tousser, étouffe..."

Qu'importe, pour Sonia, "l'âme de la France, ça a toujours été ses étrangers. Ce sont eux qui la rappellent à sa grandeur, car ils l'aiment pour ça. Il faut toujours en faire plus que les Français pour espérer devenir pleinement Français sans se renier pour autant. C'est comme ça que ses 'étrangers' tirent ce pays vers le haut".

10 Tout cela est féroce mais pas univoque. Assouline est trop subtil pour réduire ses personnages à des caricatures. Dans cette "comédie des masques", la fin de soirée laissera entrevoir quelques bien humaines fragilités. 